\title{
CONTROLADORIA JURÍDICA - THE GAME: JOGO DE SIMULAÇÃO DA GESTÃO JURÍDICA
}

\author{
CURITIBA/PR MAIO/2018
}

\author{
Antoine Youssef Kamel - UNINTER - antoine12@gmail.com \\ Daniele Assad Gonçalves - UNINTER - DANIELE.GO@uninter.com \\ Armando Kolbe Júnior - UNINTER - ARMANDO.K@uninter.com \\ Débora Cristina Veneral - UNINTER - DEBORA.V@UNINTER.COM
}

Tipo: Relato de Experiência Inovadora (EI)
Categoria: Métodos e Tecnologias
Setor Educacional: EDUCAÇÃO SUPERIOR

RESUMO

Este trabalho é um relato de experiência sobre o desenvolvimento de jogo com finalidade educativa. Apresenta-se a experiência de concepção e desenvolvimento de "Controladoria Jurídica - The Game", um jogo do tipo simulação para a gestão jurídica de um escritório de advocacia. A experiência do jogo busca mesclar, com qualidade, o entretenimento e a educação necessários em jogos educativos. Por fim, são descritos os conceitos e procedimentos adotados pelos desenvolvedores bem como os elementos considerados fundamentais em um jogo desse tipo, concluindo-se por ser viável que cada projeto de jogo para o ensino superior pode considerar e vir a implementar esses elementos.

Palavras-chave: Tecnologia aplicada à educação a distância; Jogo de simulação da gestão jurídica; Graduação em Gestão de Serviços Jurídicos e Notariais; Desenvolvimento de recursos educacionais digitais.

\section{AGRADECIMENTOS}

MUITO OBRIGADO AOS COLEGAS DA ESCOLA SUPERIOR DE GESTÃO PÚBLICA, POLÍTICA, JURÍDICA E SEGURANÇA, POR DAR FORÇA NO TRABALHO DIÁRIO, E À PROFA. DÉBORA, POR INSPIRAR O MELHOR DOS SEUS COLABORADORES. 


\section{Introdução}

Apresenta-se aqui a experiência de concepção e desenvolvimento de "Controladoria Jurídica - The Game", um jogo do tipo simulação para a gestão jurídica de um escritório de advocacia.

É um projeto inovador na medida em que a gestão jurídica tem sido pensada apenas mais recentemente. O primeiro curso superior na área, o curso superior de Tecnologia em Gestão de Serviços Jurídicos e Notariais da UNINTER, iniciou sua primeira turma em agosto de 2014, e é precisamente nele que está surgindo este primeiro jogo.

\section{Objetivos}

O objetivo deste trabalho é demonstrar a aplicação da teoria à prática no desenvolvimento de um jogo educativo do tipo simulador.

Os elementos de "Controladoria Jurídica - The Game" foram pensados sob o duplo caráter do jogo educativo, de servir à educação em suas múltiplas possibilidades ao mesmo tempo em que traz prazer ao ser jogado.

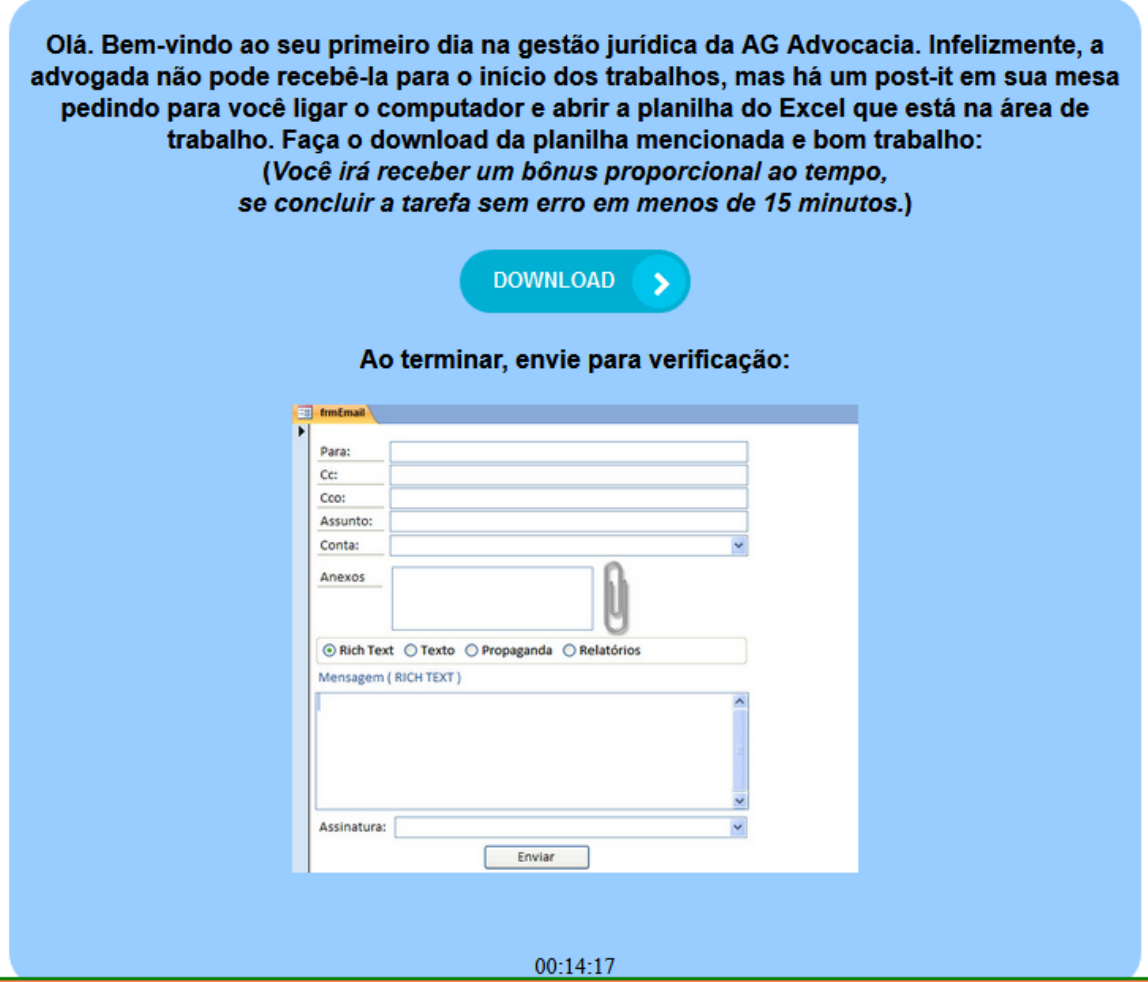

PIB Informa: Horário de trabalho: 9 às 13h - Dia: 1 - Barra de progresso: 5\% - Valor de Mercado do Profissional: R\$ 1200,00

Figura 1: Tela do jogo em que há um trabalho de organização de planilha; o jogo se passa em um contexto real com problemas 
Com isso, busca-se também inspirar educadores, pensadores e desenvolveres a criar conteúdo semelhante com eficácia, que mesclem entretenimento e educação em doses sábias; pois, se não houver educação, não serve ao propósito, e se não houver diversão, não é jogo.

\section{Referencial teórico}

O tema, que diz respeito à gestão de escritórios de advocacia e departamentos jurídicos de empresas, é pouquíssimo explorado atualmente, contando até o momento com um único livro dedicado especificamente à gestão jurídica (Albini, 2014). Para a base teórica, foram utilizados na concepção do jogo trabalhos de diversos autores (CORTELAZZO, 2013; FARIA, 2014; MATTAR, 2014, entre outros).

A educação multimídia - que se vale de diferentes canais sensoriais ao mesmo tempo —, se bem utilizada, se traduz em maior aprendizado para o destinatário. Para Mayer (2005), utilizar bem os recursos tem, como um dos pontos necessários, a estrutura coerente: excluir o que é inócuo, sons, imagens e tarefas sem relevância para o aprendizado. A aprendizagem proporcionada pela vivência é mais rápida e mais duradoura; mais eficaz.

\section{Procedimentos metodológicos}

Este trabalho é, assim, um relato de experiência, especificamente sobre o desenvolvimento de jogo com finalidade educativa, descrevendo-se os procedimentos realizados para esse desenvolvimento e teorias da educação associadas a eles.

\section{O processo de desenvolvimento do jogo}

Para o desenvolvimento do jogo, foram pensados os seus objetivos, elaborado o seu roteiro descritivo e então desenhado o storyboard.

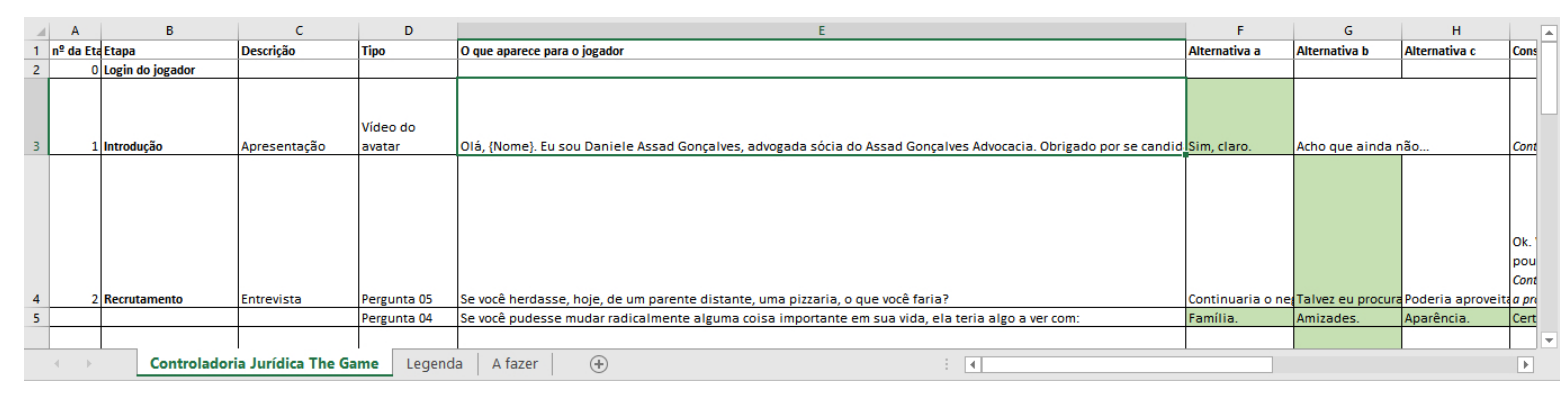

Figura 2: Uma parte do roteiro do jogo, feito em Excel. 
0. Anúncio

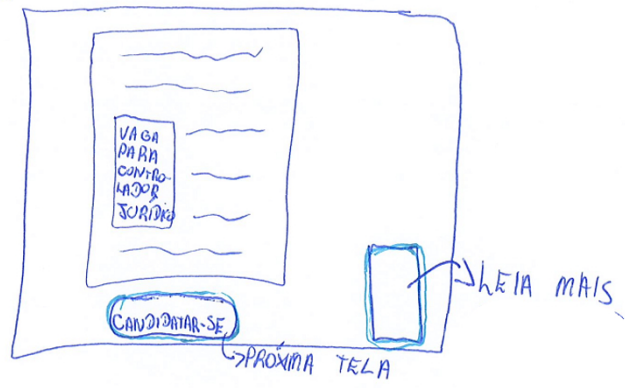

fEEDBACK DA PERGunta
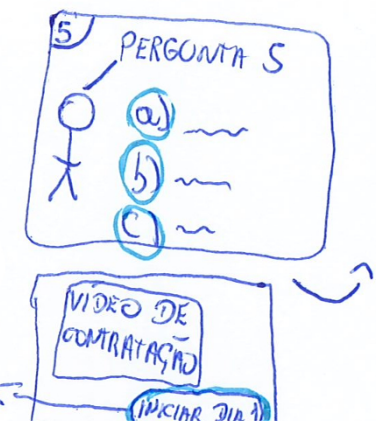

+ outra pergunta

(4) FEEDBACK. Pergunth 4

(a) -

$+\frac{\text { (b) }}{\text { (c) }-}$

.. PERgunTA 3

PER GUNTATR

Figura 3: Trecho do storyboard do jogo, demonstrando a etapa 0 (anúncio da vaga de controller jurídico) e trecho da entrevista.

É claro que essa linha tripartida de desenvolvimento (objetivo, storyboard, desenvolvimento) não é fechada e consumada, mas passa por discussões e ajustes entre uma fase e outra até a finalização do jogo, com vistas ao melhor resultado de aprendizado.

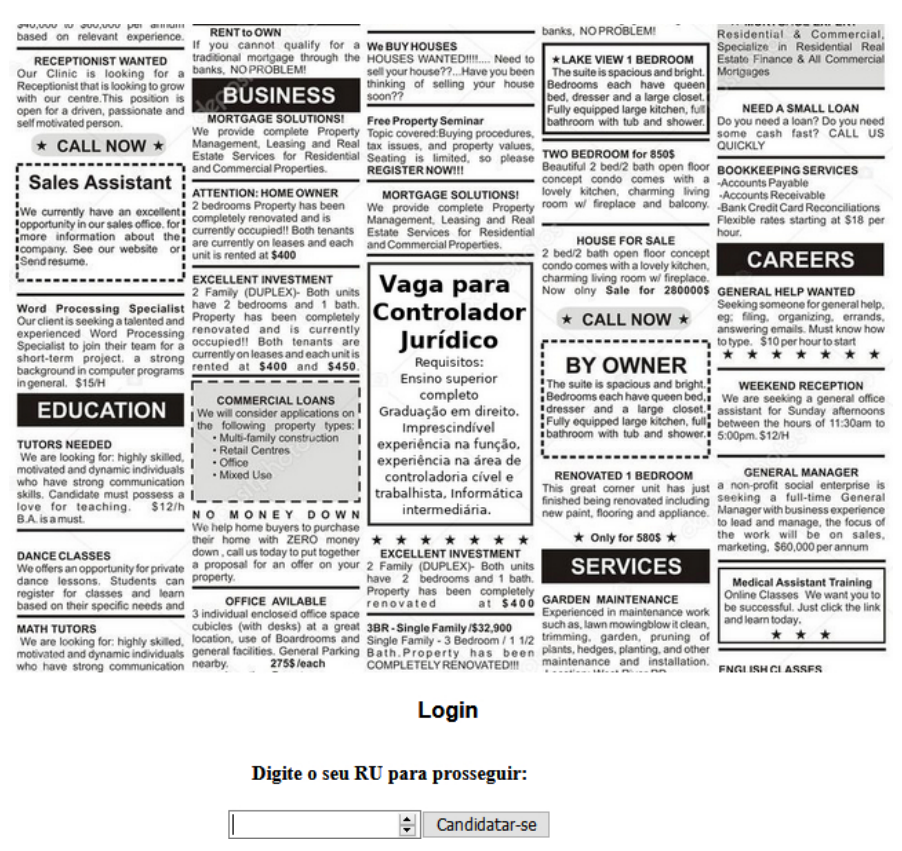

Figura 4: Implementação do jogo, isto é, tela do jogo propriamente dito, na etapa 0 (anúncio), acima demonstrada no storyboard.

Atualmente, está na fase de implementação para que em breve seja disponibilizado aos alunos do curso superior de Gestão de Serviços Jurídicos e Notariais e, futuramente, à comunidade acadêmica de modo amplo.

\section{Habilidades e competências desenvolvidas}

Foram elencadas as habilidades e competências a serem desenvolvidas no aluno do 
curso superior de Gestão de Serviços Jurídicos e Notariais no tocante à gestão jurídica, em especial na disciplina de Controladoria Jurídica e Inovação.

As habilidades a serem desenvolvidas em um gestor jurídico, conforme essa reflexão, foram fechadas em alguns pontos principais:

- Entender de maneira ampla a gestão da produção jurídica;

- Conhecer a controladoria jurídica em sua definição e posicionamento no modelo de escritório e departamento jurídico;

- Compreender as funções do gestor, assistente, estagiário, e suas rotinas;

- Entender a importância da escolha, customização e utilização de um software de gestão jurídica;

- Compreender os princípios de funcionamento de um software de gestão jurídica;

- Executar tarefas de organização e de gestão do conhecimento com foco na área jurídica;

- Confeccionar e emitir relatórios.

A partir dos objetivos acima elencados, que estão entre os esperados na formação do profissional que realiza a graduação, pensou-se em situações condizentes com a prática inicial de um gestor jurídico utilizando-se de ferramentas básicas: um navegador de internet (para executar o jogo e realizar a maioria das tarefas) e um pacote Office (para realizar algumas tarefas dentro das atribuições do gestor jurídico).

\section{Elementos da realidade}

Uma preocupação constante na elaboração e no desenvolvimento do jogo é a imersão: a adoção de recursos dialógicos e elementos típicos de jogos de simulação para que o jogo não se constitui apenas de uma tarefa seguida de outra, mas de uma experiência realista em que, ao final, o jogador se sinta vitorioso pelo aprendizado e resultados obtidos ou, por outro lado, desejoso de voltar a jogar a fim de obter um melhor resultado.

Esses elementos de ludicidade e de realidade aptos a gerar uma melhor experiência de jogo e de efetivo aprendizado, adotados na elaboração e no desenvolvimento do "Controladoria Jurídica - The Game", são, conforme concepção própria dos autores a partir de estudo dos referenciais teóricos:

a) Linguagem real: a interação principal é do jogador com sua superiora, sócia administradora do escritório jurídico para o qual o jogador é contratado (se for admitido na entrevista inicial), e a linguagem utilizada não é a de um simples jogo, mas sim o de 
uma advogada experiente com seu novo funcionário. $\mathrm{O}$ jogo teve roteiro elaborado por um advogado com auxílio de seus pares, e a personagem é representada por uma pessoa que realmente tem vivência na área (formada em Administração e em Direito), que também colabora no desenvolvimento do jogo.

b) Situações de aleatoriedade: para que a simulação não se forme um ciclo de missões a cumprir, foram adicionais elementos de realidade que não afetam o resultado. Como exemplos, a entrevista inclui uma pergunta pessoal, sem resposta correta, mas que contribui para a imersão do jogador desde o início no contexto vivenciado em sua tela; a sócia administradora precisa viajar e deixa outra advogada a cargo das instruções.

c) Retorno imediato e recompensas: mesmo as tarefas que exigem o download de tarefas em formato de planilha eletrônica mais ou menos complexas e o envio das planilhas após o devido trabalho têm correção automática pelo sistema. O retorno imediato sobre erros e acertos, especialmente se associado a recompensas (como a pontuação) melhora o nível de engajamento com a tarefa e, consequentemente, oportuniza maiores chances de aprendizado.

d) Desafio: um jogo que não é desafiador ainda é um jogo, porém, não educativo, e sim um passatempo. Um jogo que tem a (justa) pretensão de servir à educação deve trazer problemas que exigem a atenção e o raciocínio. A taxonomia de Bloom (1956) é um bom auxílio neste aspecto, ao se pensar que o jogo pode exigir desde a simples evocação da memória até a aplicação do conhecimento, como por análise e juízo crítico do conhecimento. No jogo em questão, isso é feito em nível crescente de dificuldade, a fim de não desmotivar de início os jogadores e, também, cativar a concentração e aumentar o desejo e o gosto de vencer ao final de crescentes desafios.

e) Ligação com problemas reais: se um jogo educativo tiver todas as características acima, mas não tiver nexo com a realidade, terá maior dificuldade em ser usado no ensino superior - embora possa ser muito mais adequado em outros níveis de ensino.

Por exemplo, o jogador comanda uma nave espacial que recebe instruções matemáticas e precisa atirar na resposta correta; isso traz problemas reais de matemática, mas a nave espacial é um elemento ficcional, dissociado da real operação da matemática. Um jogo como o desse exemplo evoca o raciocínio, bem como atrai a atenção dos mais novos, porém, pode não atrair o interesse dos mais velhos, os graduandos.

Em "Controladoria Jurídica - The Game", os problemas são verossímeis. Envolvem o trabalho com planilhas, decisões orçamentárias básicas, organização de processos 
jurídicos, entre outros, em um contexto de contratação e trabalho em um escritório de advocacia, o ambiente de atuação real para essa necessidade. Embora bastante simples em termos de estruturação, não é a complexidade por si só ou os gráficos que importam, mas o despertamento do interesse e a problematização, o desafio, no contexto simulado. A vivência no jogo dá maior segurança ao futuro profissional quando precisar enfrentar a realidade, bem como cria a necessidade de se aprender o conteúdo das matérias para solucionar os problemas do jogo.

O elemento "ligação com problemas reais" advém de que a realidade é fantástica quando podemos experimentá-la como jogo; assim, quase ninguém gosta de declarar o Imposto de Renda (IR), mas se tornaria uma tarefa mais divertida no início de cada ano se, alguns meses antes, o contribuinte jogasse uma simulação para declarar o IR de determinada pessoa famosa, com pontuação para cada item no campo correto e demais elementos descritos neste tópico.

Pelo que se observa de muitos jogos educativos, os problemas e situações são veiculados de modo dissociado da realidade em que se passa o jogo - um labirinto com perguntas e boxes de informação, ou um jogo do tipo quiz, ou um suspense ao estilo detetive, buscando-se pistas, para tratar de todo e qualquer tipo de tema. Pode ser difícil pensar em contexto real para determinados desafios de aprendizagem, e talvez impossível - especialmente quando se busca incentivar principalmente a memorização de informações -, mas procurar garantir a experiência de aprendizado em contextos reais vale o esforço.

f) Replay value: replay value (ou replayability, "rejogabilidade") significa o valor que um jogo tem se for jogado novamente. Esse valor é obtido principalmente pelos desafios e pelos diferentes consequências e resultados que podem ser atingidos no jogo se ele for jogado outra vez. Por isso, no jogo "Controladoria Jurídica - The Game", o trabalho do jogador irá levá-lo a um dentre três tipos diferentes de final (que consiste no feedback da superiora sobre o tempo de trabalho do novo gestor jurídico). Caso ele não obtenha a melhor pontuação, poderá tentar mais uma vez para ter o melhor feedback. Há também um ponto do jogo em que o jogador escolhe trabalhar com processos cíveis ou processos criminais, e, em uma sessão do jogo, terá apenas um deles. Se jogar novamente, terá a oportunidade de fazer o outro trabalho, incentivando-o a jogar novamente e, consequentemente, reforçar significativamente o aprendizado.

As falas para com o jogador são veiculadas por avatares e balões de texto; instruções inseridas nas próprias planilhas com que o jogador deverá trabalhar; e em vídeos gravados especificamente para o jogo. 

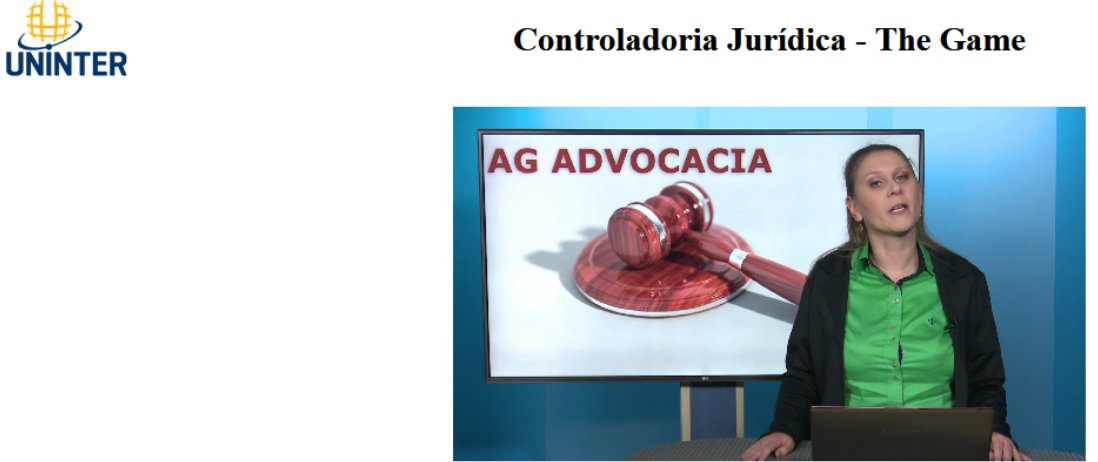

Olá. Eu sou Daniele Assad Gonçalves, advogada, sócia e administradora do AG Advocacia. Obrigado por se candidatar ao nosso processo seletivo para contratação de um gestor jurídico. Lemos seu curriculo e agora apenas queremos saber de algumas de suas habilidades e competências para exercer o cargo. Podemos começar?

Figura 5: Imagem do jogo na fase inicial da entrevista para a contratação.

Os elementos de realidade ora mencionados não afetam diretamente o aprendizado de conteúdo, porém, eles se encontram em consonância com Souza e Mansur (2016, p. 6); afirmam os autores que o emprego de tecnologia e recursos vívidos - o simples uso de mídias - não é suficiente, mas dependem de se adentrar na mente do aluno: "meras imagens, sem um direcionamento e clareza, também dificultam a compreensão do estudante. A questão está vinculada mais em como o aparelho cognitivo da pessoa funciona, do que com o próprio material em si."

Absolutamente cada avanço do jogador, por menor que seja ou pareça, não é em vão, mas tem um objetivo pensado ou (1) com base nas habilidades e competências a serem desenvolvidas, ou (2) como forma de engajar o jogador na simulação.

\section{Resultados esperados}

Não há resultados finais tendo em vista que o jogo está em desenvolvimento, porém, pode-se falar em resultados esperados. Além da aprendizagem que trará frutos à vida profissional dos presentes e futuros profissionais, a mensuração desse aprendizado permitirá será essencial para o aperfeiçoamento do jogo e da própria graduação em Gestão de Serviços Jurídicos e Notariais.

Buscar-se-á registrar as interações de cada jogador. Essas informações deverão abranger as respostas dadas a cada problema e o tempo de resposta, bem como há quanto tempo o jogador é aluno do curso e qual o desempenho dos alunos com mais tempo de curso em comparação aos calouros. 
Com a coleta e análise dessas informações a partir do lançamento do jogo, será possível não só proporcionar uma melhor formação com viés prático como, igualmente, detectar pontos de melhoria ao longo do caminho formativo do futuro gestor jurídico.

\section{Considerações finais}

Podemos dizer, com Florêncio da Silva e Oliveira (2017, p. 9) que "os métodos já consagrados de design instrucional utilizados na criação de materiais didáticos servem perfeitamente para a concepção de soluções educacionais em formato de game". A forma de criação de material para a EAD tem se desenvolvido, e as novas formas de pensar o conteúdo e a interação com o aluno são também aplicáveis, como linhas mestras ou diretrizes, também às ideias inovadoras.

Foi visto que um jogo educativo deve mesclar entretenimento e educação pois, sem objetivo educacional, não serve, e se não houver diversão, não é jogo. Os elementos descritos neste artigo, adotados pelo "Controladoria Jurídica - The Game", podem ser considerados para implantação em praticamente qualquer jogo educativo, e espera-se que venham a ser efetivados e que seus desenvolvedores mensurem e compartilhem os resultados na aprendizagem.

O processo de elaboração de um conteúdo de qualidade, qualquer espécie de conteúdo, é trabalhoso e envolve o trabalho de outras pessoas de diversas áreas. Para um jogo, em todas as suas complexidades e interações programadas, ainda mais. As ideias, o roteiro e a implementação tecnológica passaram e certamente ainda passarão por discussões e reformulações, até que se tenha, ao final, o melhor produto possível para o aperfeiçoamento prático dos estudantes.

O jogo trabalhado neste artigo está com o roteiro finalizado e atualmente se encontra na fase de desenvolvimento técnico. Ainda que sem resultados de sua aplicação aos alunos - o que se espera fazer em futuro artigo - , procurou-se aqui demonstrar 0 método de criação de um jogo com as melhores teorias e práticas sobre a educação distância e a criação e utilização de jogos educacionais no ensino superior.

\section{Referências}

ALBINI, Samantha. Controladoria Jurídica: para Escritórios de Advocacia e Departamentos Jurídicos. Curitiba: Juruá, 2014.

BLOOM, Benjamin S. Taxonomy of Educational Objectives, v. 1: Cognitive Domain. 
New York: McKay, 1956.

CORTELAZZO, Iolanda Bueno de Carmargo. Prática pedagógica, Aprendizagem e Avaliação em Educação a Distância. Curitiba: Intersaberes, 2013.

FARIA, Adriano Antônio; LOPES, Luís Fernando. Práticas Pedagógicas em EAD. Curitiba: InterSaberes, 2014.

FLORÊNCIO DA SILVA, Leonardo; OLIVEIRA, Mateus Garcia de. O Game instrucional no ensino superior: uma adaptação do editorial ciência contra o crime. In: Anais do 23을 Congresso Internacional ABED de Educação a Distância, 2017. Disponível em: <http://www.abed.org.br/congresso2017/trabalhos/pdf/317.pdf>. Acesso em: 04 maio 2018.

GONZALEZ, Mathias. Fundamentos da Tutoria em Educação a Distância. São Paulo: Avercamp, 2005.

SOUZA, Cristiane Mendes de; MANSUR, Ralph S. Cibermídias e ciberespaços para cibercérebros. In: Anais do $22^{\circ}$ Congresso Internacional ABED de Educação a Distância, $2016 . \quad$ Disponível em: <http://www.abed.org.br/congresso2016/trabalhos/90.pdf>. Acesso em: 04 maio 2018.

MATTAR, João. Design Educacional: Educação a Distância na Prática. São Paulo: Artesanato, 2014.

MAYER, Richard E. Cognitive theory of multimedia learning. In: The Cambridge Handbook of Multimedia Learning. New York: Cambridge University Press, 2005. 